\title{
STRATEGI BRAND IMAGE PROGRAM STUDI KOMUNIKASI DAN PENYIARAN ISLAM STAIN MAJENE
}

\author{
Fathiyah $^{1}$ \\ Sekolah Tinggi Aagama Islam Negeri Majene \\ Email: fathiyah@stainmajene.ac.id
}

\begin{abstract}
ABSTRAK
Memiliki image yang positif sudah menjadi tuntutan bagi setiap lembaga. Brand berarti gambaran positif yang melekat dan dingat oleh masyarakat sehingga perusaahn atau lembaga diingat untuk jangka waktu yang lama. Seperti halnya sebuah perusahaan kampus sebagai lembaga pendidikan tinggi juga dituntut untuk menciptakan image psoistif. Hal ini didasari pada sumsi bahwa masyarakat akan memilih perguruan tinggi yang memiliki keungguan dibanding dengan perguruan tinggi lainnya untuk itu keberhasilan sebuah kampus dipengaruhi oleh keberhasilan membentuk citra yang positif di masyarakat melalui kegiatan pembentukan Brand Image. Penelitian ini bertujuan untuk mengetahui 1). Faktor pembentuk band image Program Studi Komunikasi dan Penyiaran Islam STAIN Majene. 2). Dampak pembentukan brand image Program Studi Komunikasi dan Penyiaran Islam STAIN Majene. Jenis penelitian ini adalah penelitian deskripsif, kualitatif. Data diperoleh melalui taknik wawancara, observasi, wawancara dan studi kepustakaan dan menggunakan teknik analisis data model interaktif. Hasil penelitian menunjukkan bahwa Brand image Program Studi Komunikasi dan Penyiaran Islam STAIN Majene dibentuk oleh beberapa faktor yakni: Ketokohan pimpinan, tawaran beasiswa, peningkaan kerjasama dengan beberapa stakeholders, kurikulum yang ditawarkan, pengelolaan media sosial, dan program unggulan. Faktor-faktor tersebut berdampak pada semakin dikenalnya program studi komunikasi dan penyiaran Islam, dan meningkatnya peminat image Program Studi Komunikasi dan Penyiaran Islam STAIN Majene di tahun ketiga mencapai peningkatan sekitar $300 \%$.
\end{abstract}

Kata Kunci: Perguruan Tinggi; citra positif; Brand Image

\section{Brand Image Strategy of Islamic Communication And Broadcasting Programs Of STAIN Majene}

\section{ABSTRACT}

Having a positive image has become a demand for every institution. Brand means a positive image that is attached to and remembered by the community so that the company or institution is remembered for a long time. Just as a campus company as a higher education institution is also required to create a positive image. This is based on the conclusion that the public will choose a university that has excellence compared to other universities. Therefore, the success of campus is influenced by the success of forming a positive image in society through the activity of forming a brand image. This study aims to determine 1). Forming factors for band image, Islamic Communication and Broadcasting Study Program of STAIN Majene. 2). The impact of forming a brand image of the Islamic Communication and Broadcasting Study Program of STAIN Majene. This type of research is descriptive, qualitative research. The data were obtained through an interview, observation, interview, and literature study techniques and used interactive model data analysis techniques. The results showed that the brand image of the STAIN Majene Islamic Communication and Broadcasting Study Program was formed by several factors, namely: leadership, scholarship offers, increased cooperation with several stakeholders, the curriculum offered, social media management, and superior programs. These factors have an impact on the increasing recognition of the study program of Islamic communication and broadcasting, and the increasing interest in the image of the STAIN Majene Islamic Communication and Broadcasting Study Program in the third year, reaching an increase of around $300 \%$.

Keywords: University; positive image; Brand Image 
Korespondensi: Fathiyah M. I. Kom. Sekolah Tinggi Agama Islam Negeri Majene. Jl. BLK Lingk. Passarang, Totoli Kec. Banggae Kab. Majene SULBAR. No. HP, WhatsApp: 085396546586 Email: fathiyah@ stainmajene.ac.id

\section{PENDAHULUAN}

Pendidikan merupakan aspek penting yang menjadi modal besar suatu negara menghasilkan generasi penerus bangsa. Setiap siswa yang menyelesaikan studi di Sekolah Menegah Atas (SMA) memiliki keinginan untuk melanjutkan studi ditingkat Perguruan Tingi. Keputusan untuk memilih Perguruan Tinggi sebagai tempat melanjutkan pendidikan tentu akan memperhitungkan aspek untung dan rugi, karena pendidikan dianggap sebagai bentuk investasi masa depan. Masyarakat akan memilih lembaga pendidikan yang dianggap memiliki keunggulan dari lembaga pendidikan yang lain. Sehingga wajar terjadi persaingan antar lembaga pendidikan. Lembaga pendidikan yang tidak peka terhadap persaingan ia akan tertinggal dari lembaga pendidikan lain yang telah mempersiapkan diri. Sehingga setiap universitas harus memiliki strategi untuk menarik minta dari calon mahasiswa agar memilih universitas, fakultas serta jurusan yang dianggap mampu menyelesaikan persoalan - persoalan masa depan calon mahasiswa.

STAIN Majene yang berdiri pada tahun 2016 hadir sebagai bentuk perjuangan dan komitmen masyarakat SULBAR atas penetapan Majene sebagai kota pendidikan sejak resminya SULBAR menjadi propinsi. Majene menjadi alternative pilihan bagi masyarakat yang ingin melanjutkan studi, yang diharapkan mampu menghasilkan lulusan yang mampu berkontribusi nyata bagi daerah Majene.

Peningkatan jumlah pendaftar setiap tahunnya menjadi indikator bahwa STAIN Majene merupakan rujukan perguruan tinggi Islam di Sulawesi Barat. Peningkatan jumlah mahasiswa ini diharapkan dapat membawa dampak positif untuk pertumbuhan sumberdaya manusia di Kabupaten Majene. Tahun 2018 jumlah pendaftar di STAIN Majene mengalami peningkatan hampir di semua jurusan sekitar $90 \%$ dibandingkan tahun sebelumnya, namun tidak pada Program studi komunikasi dan penyiaran Islam di STAIN Majene.

Kurang populernya Program Studi Komunikasi dan Penyiaran Islam di masyarakat Sulawesi Barat khususnya masyarakat Majene menjadi salah satu variable kurangnya minat masyarakat terhadap Program Studi sebagai pilihan. Hal ini sekaligus menjadi fakta bahwa Prodi Komunikasi dan Penyiaran Islam belum memiliki citra di mata masyarakat.

Tantangan dan problem mendasar pendidikan saat ini terletak pada aspek peningkatan mutu dan perbaikan kualitas di Perguruan Tinggi termasuk perguruan tinggi Islam (Fitri, 2013). Hal ini menjadi tantangan bagi STAIN Majene dalam menentukan strategi komunikasi yang tepat agar lebih dikenal masyarakat luas.

Kampus sebagai sebuah lembaga, haruslah berupaya menciptakan image yang positif dimata masyarakat luas sebagai perwujudan ketercapaian visi misi lembaga (Afkarina, 2018). Komunikasi yang stategis adalah hal penting yang dibutuhkan oleh sebuah kampus (Amalia, 2020), program dan aktifitas lembaga harus mampu dikomunikasikan kepada khalayak luas agar lembaga dapat berkembang sesuai dengan harapan semua pihak (Mahfuzhah \& Anshari, 2018). 


\section{METODE PENELITIAN}

\section{a. Jenis Penelitian}

Penelitian ini menggunakan metode penelitian kualitatif deskriptif. Dimana data dan hasil dipaparkan dalam bentuk penjelasan deskriptif.

\section{b. Subjek Penelitian}

Subjek penelitian adalah orang-orang yang menjadi informan dalam suatu penelitian (Sugiono, 2010:115). Subjek dan informan dalam penelitian ini adalah:
a) Ketua STAIN Majene,
b) Wakil ketua I, II, dan III STAIN Majene
c) Ketua Jurusan Usluhuddin, Adab, dan Dakwah
d) Ketua Program Studi Komunikasi dan Penyiaran Islam
e) Mahasiswa Program studi Komunikasi dan Penyiaran Islam

\section{c. Waktu dan Lokasi Penelitian}

Penelitian ini dilaksanakan di STAIN Majene kabupten Majene Provinsi Sulawesi Barat. Penelitian ini dilaksanakan pada bulan Mei 2019 sampai dengan bulan November 2019.

\section{d. Pengumpulan Data}

Pengumpulan data yang dilakukan ada tiga metode, yaitu observasi, wawancara dan studi kepustakaan dan menggunakan teknik analisis data model interaktif. Jika data yang terkumpul masih kurang memadai maka peneliti melakukan teknik pemeriksaan data agar penelitian tidak bias. Teknik pemeriksaan keabsahan data yang digunakan adalah triangulasi.

\section{e. Analisis Data}

Pengumpulan data yang dilakukan ada tiga metode, yaitu observasi, wawancara dan studi kepustakaan dan menggunakan teknik analisis data model interaktif. Jika data yang terkumpul masih kurang memadai maka peneliti melakukan teknik pemeriksaan data agar penelitian tidak bias. Teknik pemeriksaan keabsahan data yang digunakan adalah triangulasi. Triangulasi data dilakukan dengan tiga cara yakni reduksi data, penyajian data dan penarikan kesimpulan (Apriliani et al., 2020). Data yang diperoleh dicocokkan antara hasil wawancara dengan data yang diperoleh dari hasil observasi ataupun sebaliknya

\section{HASIL DAN PEMBAHASAN}

Brand berarti gambar yang dapat diingat oleh publik, yang membuat merek positif, relevan dan mudah diingat sehingga bermanfaat bagi perusahaan dalam jangka waktu yang lama (Alif Fianto et al., 2014).

Branding merupakan sebuah elemen kunci dari strategi pemasaran, brand yang baik akan membantu membangun indentitas perusahaan di pasar, serta menjaga pelanggan yang solid (Desmipian et al., 2014) 
Brand Image merupakan persepsi konsumen terhadap sebuag produk dan karakter organisasi yang melibatkan ikatan emosional serta nilai-nilai. Citra yang psitif akan meningkatkan popularitas sebuah produk $(\mathrm{Oy}, 2015)$

\section{Faktor Pembetukan Brand Image Prodi Komunikasi Dan Penyiaran Islam STAIN Majene.}

Berdasarkan hasil, dokumentasi, dan wawancara diketahui bahwa pembentukan brand image Program Studi Komunikasi dan Penyiaran Islam yaitu:

a) Ketokohan Pimpinan

Kepemimpinan adalah faktor penting dalam pembentukan image sebuah institusi dengan kata lain pemimpin sebuah institusi secara tidak langsung menjalankan fungsi PR sebuah lembaga. Untuk itulah seorang pemimpin dituntut untuk memiliki kemampuan komunikasi yang startegis dan memilki pengaruh dimata publik terhadap lembaga yang dipimpinnya (Trioctavia dkk. 2016).

Dalam upaya menyerap peminat pada program studi aspek ketokohan pimpinan menjadi undur yang sangat penting. HN mahasiswa KPI angkatan ke dua memaparkan bahwa memilih prodi KPI karena tawaran dari salah satu pimpinan STAIN Majene yang selama ini dikenal sebagai sosok yang baik dan cukup dipandang masyarakat.

Memilih kuliah di STAIN Majene dan Prodi KPI karena alasan telah mengetahui sosok pimpinan STAIN juga dikemukanan oleh UM mahasiswa angkatan kedua. Pengaruh tersebut karena pengaruh pengetahuan orang tua tentang sosok pimpinan yang menurutnya sosok pimpinan STAIN Majene adalah figur yang cukup dianggap penting dan terpandang di Sulawesi Barat.

b) Tawaran Beasiswa

Beasiswa merupakan unsur penting dalam pembentukan image prodi KPI bahkan STAIN Majene secara umum. Keberadaan kampus STAIN MAjene sebagai lembaga pendidikan tinggi negeri dibawah naungan Departemen Agama menimbulkan minat yang besar bagi para orang tua untuk menyelokalahkan anaknya pada jenjang pendidikan yang lebih tinggi.

Beasiswa menjadi alasan bagi sebagaian orang tua untuk mendukung pendidikan anaknya di STAIN Majene, terutama di Prodi KPI. Hal ini dikemukakan oleh HT orang tua mahasiswa KPI angkatan pertama WD, HT mengemukakan bahwa ia memberi izin kepada WD untuk kuliah karena pernah mendengar di STAIN Majene ada beasiswa, sehingga hal tersebut menjadi penyemangat HT untuk menyekolahkan anaknya yang kini telah memasuki semester 5 .

c) Kurikulum

Lembaga pendidikan yang berkualitas harus memiliki kualifikasi kurikulum yang mampu membekali para peseta didik dengan kemampuan yang akan siap berkompetisi setelah menjadi lulusan. 
Sejak 2018 kurikulum pada program Studi Komunikasi dan Penyiaran Islam telah disusun berdasarkan Kerangka Kualifikasi Nasional Indonesia (KKNI) dimana muatannya bertujuan untuk mengintegrasikan pendidikan dan pelatihan sehingga diharapkan akan menghasilkan lulusan yang produktif dan profesional.

d) Peningkatan kerjasama dengan berbagai stakeholder.

Sejak berdirinya STAIN Majene telah mendapat dukungan dari berbagai pihak, tidak terkecuali dengan program studi Komunikasi dan Penyiaran Islam. Beberapa instansi pemerintah maupun non pemerintah telah menjadi mitra program Studi Komunikasi dan Penyiaran Islam.

Beberapa lembaga pemerintah dan non pemerintah yang saat ini telah menjalin kerjasama dengan Program Studi Komunikasi dan Penyiaran Islam dalam bentuk MOU dan MOA yaitu:

1. Dinas komunikasi, Informatika, Persandian dan Statistik Kabupaten Majene

2. Radio Mammis FM Pemkab Majene

3. Kantor Urusan Agama kec. Banggae Kabupaten Majene

4. Kantor Urusan Agama kec. Banggae Timur Kabupaten Majene

5. Madrasah Aliyah Negeri 1 Majene

6. Madrasah Aliyah Negeri 1 Polman

7. Pondok Pesantren Al-Ikhlas lampoko Campalagian, Polman

8. Pondok Pesantren Syekh Hasan Yamani

9. Komisi Penyiaran Indonesia Daerah (KPID) Sulawesi Barat.

e) Pengelolaan Media Sosial

Kotler dan Koller menggambarkan Media sosial sebagai sarana komunikasi yang berisi teks, gamabr audio serta video yang dapat menjadi sarana komunikasi dan interaksi antara perusahaan dan masyarakat dan mudah diakses (Anizir; Wahyuni, 2017)

Manfaat penggunaan sosial media sebagai media promosi adalah yang hal yang tidak diragukan lagi. Saat ini akun sosial media instagram dan fanpaeg FB, dikelola oleh prodi KPI bekerjasama dengan mahasiswa.

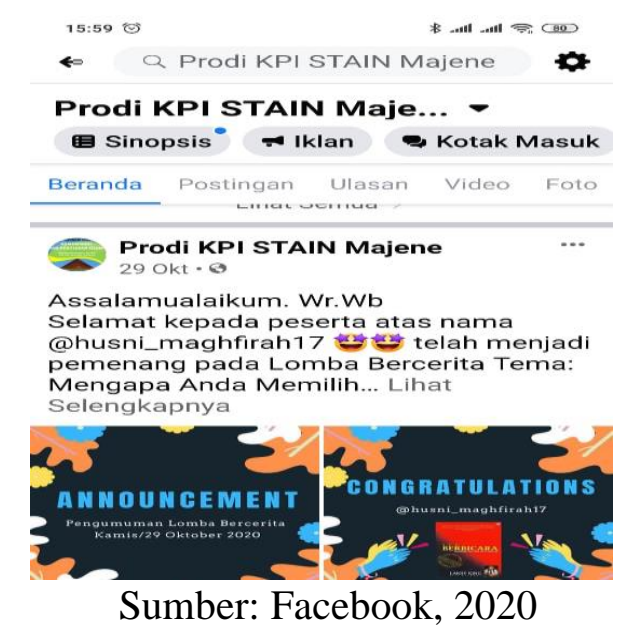

Gambar 1. Akun Fanpage FB prodi KPI 


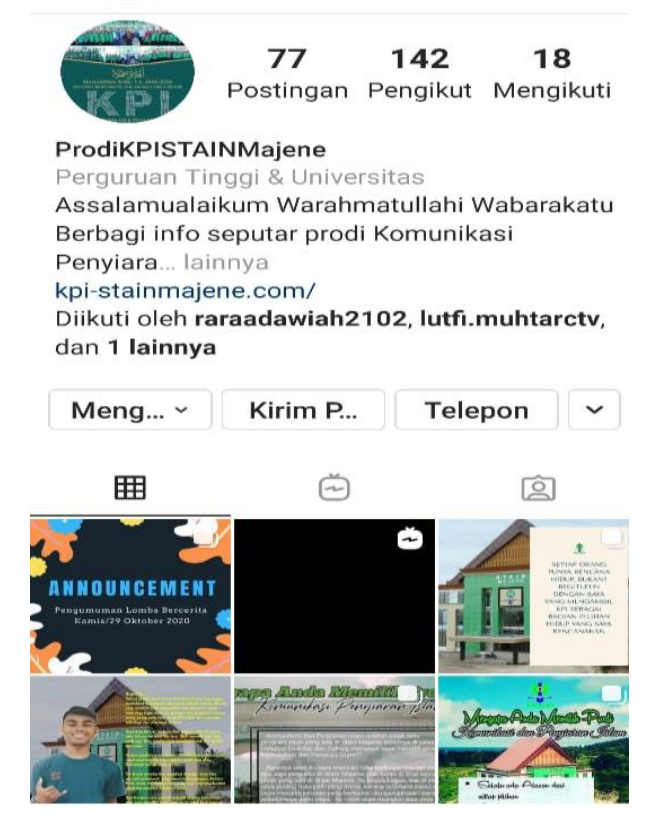

Sumber: Instagram, 2020

Gambar 2: Akun Instagram prodi KPI

Kehadiran media sosial menjadi jembatan informasi antara pihak prodi KPI dengan masyarakat luas, terutama bagi para calon mahasiswa baru.

Pengelolan media sosial dianggap penting oleh prodi KPI karena menyadari para calon mahasiswa adalah golongan milenial yang akrab dengan aktifitas media sosial

f) Kegiatan Unggulan

Saat ini mahasiswa Program Studi Komunikasi dan Penyiaran Islam membentuk sebuah lembaga studi club KOMPAK (Komunitas Pengembangan Tripotensi Mahasiswa KPI).

Studi KOMPAK dibentuk untuk mewadahi para mahasiswa dalam mengembangkan kemampuan dalam bidang public speaking, broadcasting, serta writing yang diharapkan mampu menjadi bekal dalam mempersipkan diri untuk terjun di bidang komunikasi dan penyiaran.

\section{Dampak pembentukan brand image Prodi Komunikasi dan penyiaran Islam STAIN.}

Penelitian ini menunjukkan bahwa pembentukan brand image prodi KPI berdampak pada dua hal yakni: Prodi KPI semakin dikenal, serta peningkatan minat masyarakat terhadap prodi KPI .

Langkah strategis pembentukan brand image yang dilakukan program studi komunikasi dan penyiaran Islam sebagaimana yang telah dipaparkan diatas, diakui telah membawa dampak semakin dikenalnya eksistensi Prodi KPI di masyarakat Sulawesi Barat dan masyarakat Majene pada khususnya.

Massifnya pemberitaan melalui media sosial semakin memudahkan STAIN Majene dalam menyebarkan informasi kepada masyarakat. STAIN Majene juga kerap menghiasi media cetak lokal sehingga semakin membentuk citra yang positif di mata masyarakat.

Mahasiswa adalah objek sekaligus subjek dalam proses belajar mengajar pada perguruan tinggi. Mahasiswa adalah seseorang yang terdaftar dan menempuh pendidikan pada perguruan tinggi, akademik, politeknik, sekolah tinggi, institut dan universitas (Hartaji, 2012: 5). 
Peningkatan minat pendaftar pada Program Studi Komunikasi Dan Penyiaran Islam menjadi tolok ukur tingginya kepercayaan masyarakat untuk menjadikan prodi KPI sebagai pilihan untuk melanjutkan pendidikan sekaligus menunjukkan bahwa saat ini Program Studi KPI memiliki image yang positif dimata masyarakat.

Tabel 1 Data Perkembangan Mahasiswa Prodi KPI STAIN Majene

\begin{tabular}{lll}
\hline Tahun Ajaran & $\begin{array}{l}\text { Jumlah } \\
\text { Mahasiswa } \\
\text { Baru }\end{array}$ & $\begin{array}{l}\text { Total } \\
\text { Mahasiswa }\end{array}$ \\
\hline $2017 / 2018$ & 20 & 20 \\
\hline $2018 / 2019$ & 33 & 33 \\
\hline $2019 / 2020$ & 103 & 103 \\
\hline & TOTAL & 167
\end{tabular}

Sumber: Akademik STAIN Majene, 2019

\section{Grafik 1. Data Perkembangan Mahasiswa Prodi KPI STAIN Majene}

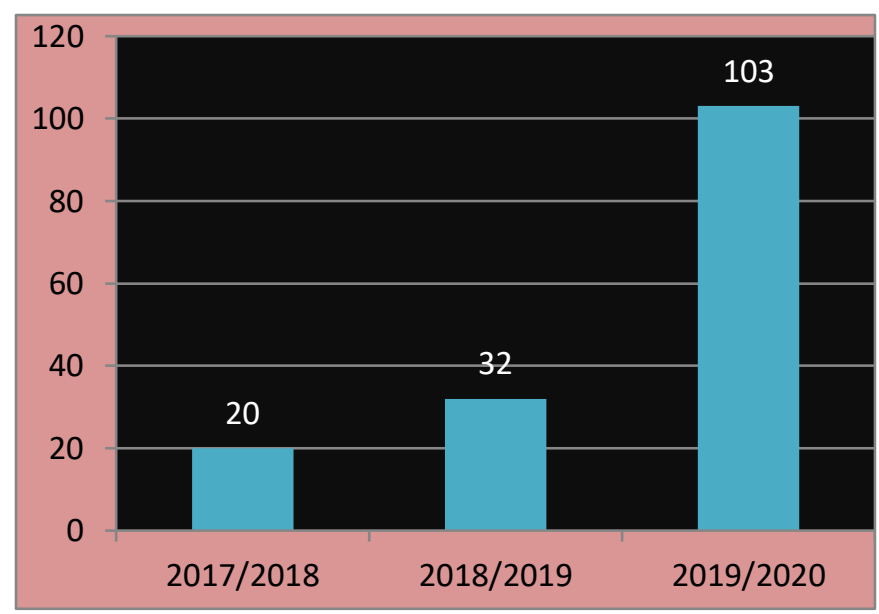

Berdasarkan tabel dan grafik diatas dapat disimpulkan bahwa dalam kurung waktu tiga tahun ini terjadi kenaikan jumlah mahasiswa dari tiga atahun penerimaman mahasiswa. Peningkatan jumlah mahasiswa tahun ajaran 2017/2018-2018/2019 mengalami peningkatan sekita 16.\%. Sedangkan pada tahun ajaran 2018/2019 mengalami peningkatan sebesar $300 \%$.

Status lembaga pendidikan Negeri yang berada dibawah naungan Depatmenen Agama menjadi spirit bagi prodi KPI untuk terus berbenah dan mengembangkan segala aspek yang bertujuan bukan hanya agar Prodi ini semakin dikenal tetapi berusaha untuk menjadi apa yang diharapkan masyakat.

Program Studi Komunikasi dan Penyiaran Islam berupaya mengelola harapan para mahasiswa dan orang tua yang telah memilih Prodi KPI dengan memberikan kepuasan sehingga berdampak pada kepercayaan dan timbulnya brand awereness masyatakat sebagai konsumen yang menikmati produk prodi KPI.

Melalui upaya yang terencana dan sistemastis dalam meningkatkan mutu dan keunggulan layanan prodi masyarakat akan berdampak pada kepuasan masyarakat sehingga akan menjadikan prodi KPI sebagai pilihan pertama dalam memilih Perguruan Tinggi. 


\section{SIMPULAN}

Strategi pembentukan brand image Program Studi Komunikasi dan Penyiaran Islam dilakukan melalui tahapan yang panjang yakni sejak awal beroperasi STAIN Majene di tahun 2017. Langkah yang dilakukan oleh prodi KPI terintegrasi pada kebijakan kampus STAIN Majene, sehingga sebagian besar langkah strategis yang diambil oleh pihak kampus telah mencakup kebutuhan pembentukan Brand image prodi KPI.

Strategi pengenalan prodi secara spesifik dilakukan pada tahun ketiga penerimaan mahasiswa, adapun faktor pembentukan brand image prodi KPI adalah: Ketokohan pimpinan, Kurikulum, Pengelolaan media sosial, dan kegiatan unggulan.

Faktor diatas dilakukan dengan menetapkan beberapa langkah yang dianggap strategis, dan pada akhirnya memberikan dampak semakin dikenalnya program studi komunikasi dan penyiaran Islam, dan meningkatnya peminat program stdui komunikasi dan penyiaran Islam di tahun ketiga mencapai peningkatan sekitar $300 \%$

Kegiatan branding image adalah kegiatan yang harus dilakukan dengan penuh perencanaa, sehingga membutuhkan dukungan dari berbagai elemen kampus agar dapat mencapai hasil yang maksimal. Untuk itu dibutuhkan kerjasama antar pihak perencanaan, unsur pimpinan kampus, jurusan dan program studi dalam menetapkan dan melaksanakan kegiatan branding image.

\section{DAFTAR PUSTAKA}

Afkarina, N. I. (2018). Strategi Komunikasi Humas Dalam Membentuk Public Opinion Lembaga Pendidikan. Idaarah: Jurnal Manajemen Pendidikan, 2(1), 50-63. https://doi.org/10.24252/idaarah.v2i1.5124

Alif Fianto, A. Y., Hadiwidjojo, D., Aisjah, S., \& Solimun, S. (2014). The Influence of Brand Image on Purchase Behaviour Through Brand Trust. Business Management and Strategy, 5(2), 58. https://doi.org/10.5296/bms.v5i2.6003

Amalia, V. (2020). STRATEGI KOMUNIKASI HUMAS DALAM MENINGKATKAN PUBLIC TRUST DI PERGURUAN TINGGI (Studi Kasus di Universitas Nurul Jadid, Paiton, Probolinggo). $A L$ TANZIM: Jurnal Manajemen Pendidikan Islam, 4(1), 13-23. https://doi.org/10.33650/altanzim.v4i1.812

Anizir; Wahyuni, R. (2017). Pengaruh Social Media Marketing Terhadap Brand Image Perguruan Tinggi Swasta Di Kota Serang. Jurnal Sains Manajemen, 3(2), 0. http://ejurnal.lppmunsera.org/index.php/SM/article/view/25

Apriliani, M., Rusdiyani, I., \& Sayekti, T. (2020). AND CIRCLE TIME ) BERBASIS KECERDASAN JAMAK ( Penelitian Deskriptif Kualitatif di TK Islam Tirtayasa Kota Serang ). JPP PAUD FKIP Untirta, 7(November 2020), 145-158.

Desmipian, D., Sulthan, M., \& S.R, D. B. (2014). Branding Perguruan Tinggi Negeri Studi Kasus Strategi Marketing Public Relations Universitas Jenderal Soedirman. 10 No, 2, 97-105.

Fitri, A. Z. (2013). MASA DEPAN PERGURUAN TINGGI ISLAM: Membangun Visi Kelembagaan Bereputasi Internasional. Epistemé: Jurnal Pengembangan Ilmu Keislaman, 8(2), 235-258. https://doi.org/10.21274/epis.2013.8.2.235-258

Mahfuzhah, H., \& Anshari, A. (2018). Media Publikasi Humas Dalam Pendidikan. Al-Tanzim : Jurnal Manajemen Pendidikan Islam, 2(2), 137-149. https://doi.org/10.33650/al-tanzim.v2i2.395

Oy, C. L. (2015). 1: Image and Identity. 33-53. https://doi.org/10.1484/m.miscs-eb.4.2017003

Sugiyono, 2010, Metode Penelitian Pendidikan Pendekatan Kuantitatif, Kualitatif. Bandung: Alfabeta 